\title{
Will My Disclosure Harm the Relationship? Factors that Impact Mother-Daughter Cancer Communication in Taiwan
}

\author{
Wan-Lin Chang ${ }^{1}$ \\ The University of Texas, Rio Grande Valley
}

\begin{abstract}
Since 1982, cancer has been the leading cause of death in Taiwan. According to the Ministry of Health and Welfare (2020), in 2019 more than a quarter (28.6\%) of deaths were caused by cancer, an increase of about $5 \%$ from 1999. Family communication can help encourage social and physical support, especially for those who face traumatic, life-changing events, such as receiving a cancer diagnosis. However, people may avoid self-disclosing information about their diseases, treatments, and emotions with their families for different reasons. Between May and July 2014, fifteen in-depth interviews were conducted to explore what factors influence breast cancer mothers' desire to engage in cancer communication with their daughters. Six themes representing individual factors, relational factors, and cultural factors that influence self-disclosure emerged. These themes were: 1) Cancer stage when the mother was first diagnosed, 2) Mother's dependency/Daughter's maturity, 3) Philosophy of "face it, accept it, deal with it, and let it be”, 4) Societal expectations of women's roles, 5) Religion, and 6) Support group engagement.
\end{abstract}

KEYWORDS: Breast Cancer, Mother-Daughter Communication, Mother-Daughter Relationships, Mother-Daughter Self-Disclosure, Taiwan.

Communication, including verbal and non-verbal, is the foundation of relationship building. Without communication, relationships cannot fully develop, and this also holds true in the family setting. Family communication and relations within the family are interrelated. It is through communication that family members cultivate and build their relationships (Vangelisti, 2004, p.x). Family communication also helps encourage social and physical support, especially for those who face traumatic, life-changing events, such as receiving a cancer diagnosis. Since 1982, cancer has been the leading cause of death in Taiwan, claiming over 30,000 lives annually. In 2013, cancer accounted for 29\% of all Taiwanese deaths (Ministry of Health and Welfare, 2014). For certain families facing a cancer diagnosis, communication within the family helps them cope together and support each other, emotionally and physically, from diagnosis through treatment. This intense process requires family members to constantly adjust their attitudes toward each other and the affected family member (Mallinger et al., 2006). In short, effective family cancer communication is important to not only the patients/survivors but also to their relatives.

The topic of breast cancer can change the usual communication boundaries between family members. Some breast cancer patients experience feelings of inadequacy in their roles as wife and as mother. Like many other Asian cultures, Taiwanese society expects a mother to nurture her children to be well, healthy, and successful (Peng, 2008). A diagnosis of breast

1 Corresponding Author E-mail: wanlin.chang@utrgv.edu 
cancer can signify to society that a mother has failed to properly perform her pivotal childrearing role. This type of social norm can cause many breast cancer mothers to be unwilling to disclose their personal cancer experiences with their family members since these disclosures may negatively influence their children's current and future positions in school or the workplace.

This study investigated communication between Taiwanese breast cancer mothers and their daughters. There is a higher level of interdependence and emotional connection between the mother and daughter dyad when compared with other intergenerational relationships (Fisher, 1991). The study sought to understand what factors influence breast cancer mothers' desire to engage in cancer communication with their daughters.

\section{Review of Literature}

\section{Family Communication and Breast Cancer Research}

In Taiwan, the subject of communication is a relatively new domain of social scientific research. Family communication, let alone family cancer communication, has never caught the attention of researchers in Taiwan. Previous findings have demonstrated that family communication has not been previously considered partly due to cultural and social biases. In Chinese culture, which shares similar cultural values, norms, and traditions with Taiwan, "clear boundaries of self-disclosure exist in family" (Gao, 1996, p.96). In other words, Chinese are usually highly reluctant to disclose their personal or family information to people who are outsiders; furthermore, Chinese usually avoid topics that are controversial or face-threatening (Chen \& Yo, 2001, p.160), whether outside or within the family. Issues related to cancer or other traumatic diseases are often considered "bad luck" and controversial topics that would make average Chinese people and their family members feel too uncomfortable to discuss with each other thus constraining any substantive discussions regarding the health of the patient.

Compared to Taiwan, the United States has conducted many studies of family communication and health. Most of those studies focused on dyadic relationships such as marital relationships (Badr \& Taylor, 2006; Manne et al., 2010) or parent-child relationships (Roberts et al., 2010; Rodriguez et al., 2012). Specific to breast cancer, most research focused on how marital couples cope after cancer diagnosis (Lichtman et al., 1998; Milbury \& Badr, 2013), or on mother-daughter communication about the importance of health prevention and health education (Sinicrope et al., 2009; Gaber et al., 2013). Recently, family communication research regarding genetic counseling has become more and more popular as advances in genetic testing, including those that can now predict the probability of breast cancer, have changed the landscape of cancer research (Goodwin et al., 2001; West et al, 2001; Frank et al., 2008).

A family member's illness impacts the entire family; however, much of the breast cancer literature is primarily dedicated to presenting breast cancer patients/survivors as victims in need of emotional support from other people. The needs and coping of families of those breast cancer patients is a less investigated area, but the research that has been done demonstrated that families also need emotional and social support to cope with the situation (Bigatti et al., 2011). Breast cancer patients can serve as positive role models such as fighters against cancer and educators to other people, but very little literature views them from this angle. Using breast cancer patients/survivors as a channel to provide health information and popularize the idea of health preventive behaviors may have significant influence on their family members, who have high risk of being diagnosed with breast cancer themselves (Tercyak et al., 2013). 


\section{Factors That Influence Self-disclosure}

In general, disclosing one's personal cancer situation and experiences with loved family members not only generates social and emotional support for the cancer patient; it also serves to educate family members. Many factors influence an individual's willingness to disclose her private information. These include individual factors such as personality and personal identity; relational factors such as liking and closeness of the disclosure recipient; and cultural factors like social norms all have different levels of influence on disclosure.

\section{Individual Factors}

Individual differences can influence individuals' ability and willingness to disclose personal information to others (Jourard, 1971). Demographic variables, such as age and marital status affect a person's disclosure tendencies. Also, various personality factors, such as extroversion or introversion, social desirability, and anxiety all have some level of influence on one's desire to self-disclose (Meleshko \& Alden, 1993). Besides demographic variables and personality, cancer patients' self-identity also has an influence on personal desire to selfdisclose. An individual's identity is based on group memberships that he/she belongs to (Gudykunst \& Shapiro, 1996). Once diagnosed with breast cancer, individuals usually consider their identity temporarily or permanently altered and seek support from people or groups with similar identities (Till, 2003; Montazeri et al., 2001).

\section{Relational Factors}

Individuals' willingness to disclose information about their own condition is closely related to the quality of their interpersonal relationships. Both senders and receivers play critical roles in the process of self-disclosure. Likeability and closeness of the receivers strongly influence the message senders' willingness to disclose because people usually disclose more if they like the receivers (Collins \& Miller, 1994). In addition, receivers' feedback and responses are also influential. Senders will most likely avoid self-disclosure if they have fears of a negative response or judgment (Petronio, 2002).

\section{Cultural Factors}

Individuals' willingness to disclose personal information varies across contexts in which the interaction takes place, and culture, in which individuals develop their ethical values. Each culture has its own rules and customs that govern the norms of self-disclosure and privacy (Guerrero et al., 2014). Culture influences an individual's ability or desire to self-disclose, because culture itself is "manifested in persons' communication patterns" (Chen, 1995, p.85). According to Hofstede (1980), the Chinese culture, which is similar to the Taiwanese culture, is collectively oriented while the American culture is more individually oriented. Compared with Americans, Chinese people are less likely to disclose topics such as opinions, interests, work, financial issues, and personality with their friends and significant others (Chen, 1995, p.88). Cahn (1984) found that Americans are open to talk about intimate topics such as marriage, love, dating, sex, and emotions, while Chinese people usually feel uncomfortable discussing personal habits, beliefs, desires, family life, and family problems (Shenkar \& Ronen, 1987). 


\section{Research Question}

Many reasons affect an individual's willingness to disclose his or her condition, even within close family relationships. This study sought to address three components-individual factors, relational factors, and cultural factors - and their relation to patterns of self-disclosure. An individual's willingness to disclose is not decided solely by a single factor. Most of the time, factors from all three levels interact with one another and result in a complicated process of influence. Hence, this research sought to answer the following question:

What role do individual, relational, and cultural factors play in the self-disclosure of information that Taiwanese breast cancer mothers share with their daughters?

\section{Research Method}

\section{Sampling and Recruitment Procedure}

Between May and July 2014, fifteen in-depth interviews were conducted. Participants were contacted either by telephone or in person through personal contact and participant referral. Once the women agreed to participate in the study, the researcher would set up a time suitable for the interviewees. Interviews took place at a location of the participants' choice and convenience. The length of the interviews averaged 70 minutes and ranged between 50 and 100 minutes.

The age at which women are diagnosed with breast cancer has a significant impact on their focuses, needs, and experiences which ultimately impact their disclosure intention and content (Kroenke et al., 2004). Therefore, this study recruited at least two breast cancer mother participants in each decennial range from age 30 to 80 . Participants' basic demographic information is shown in Table 1.

\section{Table 1}

Demographic Characteristics of Breast Cancer Mothers

\begin{tabular}{llll}
\hline Current Age & & $\mathrm{N}$ & $\%$ \\
& $30-39$ & 2 & $13.3 \%$ \\
& $40-49$ & 4 & $26.6 \%$ \\
& $50-59$ & 4 & $26.6 \%$ \\
\hline Cancer Stage & $60-69$ & 3 & $20 \%$ \\
& 70 and above & 2 & $13.3 \%$ \\
\hline Education Level & Stage 0 & 2 & $13.3 \%$ \\
& Stage 1 & 3 & $20 \%$ \\
& Stage 2 & 5 & $33.3 \%$ \\
& Stage 3 & 4 & $26.6 \%$ \\
& Stage 4 & 1 & $6.7 \%$ \\
\hline Religious Belief & Under Middle School & 5 & $33.3 \%$ \\
& High School Graduate & 4 & $26.6 \%$ \\
& Associate Degree & 2 & $13.3 \%$ \\
& College and above & 4 & $26.6 \%$ \\
\hline Occupation & Buddhism \& Taoism & 7 & $46.7 \%$ \\
& Christianity \& Catholicism & 4 & $26.6 \%$ \\
& No Religion & 4 & $26.6 \%$ \\
\hline
\end{tabular}

$N=15$ 


\section{The Interview Process}

The in-depth interviews were semi-structured, and a list of questions was prepared in advance. Participants were first given questions that could easily answer, such as demographic information, when and at what stage they were diagnosed with breast cancer as well as their current cancer status. Then the interview proceeded to more difficult questions including their interpersonal relationship with their daughters and their willingness and concerns about selfdisclosing. Next, the interview focus shifted to the details of the participants' experiences and opinions about the role of women in the society, and how society's expectations influence their behavior as a mom.

\section{Data Analysis}

The purpose of qualitative research is to explore an issue or describe a pattern of interaction (Marshall \& Rossman, 1995). In addition to interview transcription, the researcher also took notes, which included observations and reflections captured during the interviews. Transcriptions were verbatim; however, to clarify quotes, some extraneous phrases or pleonasm such as "I mean" or "well..." were removed during the coding process.

Data analysis followed grounded theory's three coding phrases-open coding, axial coding, and selective coding (Strauss \& Corbin, 1990). The researcher first examined the transcripts and notes to discover categories (open coding), next marked sections of text that indicated a pattern and used constant comparison method to further develop the 17 categories (axial coding). The researcher then integrated and refined the theory (selective coding), and finally collapsed these categories into six themes.

These three coding phrases were not necessarily sequential, but rather iterative until a coherent understanding emerged (Strauss \& Corbin, 1998). After finalizing six themes, the researcher returned to the transcripts to review participants' statements to choose the quotes that best represented these themes. Examining these quotes provided a more detailed understanding of participants' experiences. Table 2 demonstrates the coding processes for the study.

Table 2

The Framework of Coding Process of Mother Interviewees

\begin{tabular}{lllll}
\hline & Open Coding & Axial Coding & Axial Coding & $\begin{array}{l}\text { Selective } \\
\text { Coding }\end{array}$ \\
\hline $\begin{array}{l}\text { Initial read } \\
\text { through text }\end{array}$ & $\begin{array}{l}\text { Identify specific } \\
\text { segments of } \\
\text { information }\end{array}$ & $\begin{array}{l}\text { Label the } \\
\text { segments of } \\
\text { information to } \\
\text { create categories }\end{array}$ & $\begin{array}{l}\text { Reduce overlap } \\
\text { and redundancy } \\
\text { among the } \\
\text { categories }\end{array}$ & $\begin{array}{l}\text { Create a model } \\
\text { incorporating } \\
\text { most important } \\
\text { categories }\end{array}$ \\
\hline $\begin{array}{l}118 \text { pages of } \\
\text { text }\end{array}$ & $\begin{array}{l}\text { Many segments } \\
\text { of text }\end{array}$ & $\begin{array}{lll}17 \text { categories } \\
11 \text { categories }\end{array}$ & 6 categories \\
\hline
\end{tabular}

Framework adopted from Creswell, 2012

\section{Findings}

Among fifteen participants, nine were living with their daughters and all of them considered themselves close with their daughters. When the researcher asked all the mothers, "How do you view your mother-daughter relationship compared with other families?" all of them either answered closer than or about the same as other families. Going further, the research asked what topics the mothers typically discussed with their daughters. Though several topics were mentioned, the majority of the mother/daughter discussions centered on activities of their daily lives. Only a few, mainly mothers who are not cohabitating with daughters, mentioned 
discussing cancer related issues, and these discussions mainly consisted of nutrition or daily regimen components, not on deeper, more personal emotions. The researcher deduced that mothers may choose discussions devoid of emotional content to avoid too personal topics that may negatively influence their daughters' moods or emotions.

Based on the literature, factors that influence individual's disclosure intention can be grouped into three different levels: individual, relational, and cultural. Additionally, the six themes discovered in this study can be categorized into one of these three levels with some cutting across multiple levels. Table 3 presents the mapping of the six themes onto the three different levels. Below provides a detailed information and explanation along with quotations to support these themes.

\section{Table 3}

Relationship Between Themes and Levels of Factors That Influence Individual's Disclosure

\begin{tabular}{llll} 
& $\begin{array}{l}\text { Individual } \\
\text { Level }\end{array}$ & $\begin{array}{c}\text { Relational } \\
\text { Level }\end{array}$ & $\begin{array}{c}\text { Cultural } \\
\text { Level }\end{array}$ \\
\hline 1. Cancer stage when the mother was first diagnosed & $*$ & & $*$ \\
2. Mother's dependency/Daughter's maturity & $*$ & $*$ & $*$ \\
3. Philosophy of "face it, accept it, deal with it, and let & & $*$ \\
it be" & & $*$ \\
4. Societal expectation on women's role & $*$ & $*$ \\
5. Religion & $*$ & $*$ & \\
6. Support group engagement & $*$ & & $*$ \\
\hline
\end{tabular}

\section{Cancer Stage When Breast Cancer Mothers Were First Diagnosed}

The diagnosis stage (0-4) indicates the severity of the breast cancer and how threatening it is to an individual's life. Cancer stage also influences the individual's disclosure topic choice, frequency, duration, and depth. Taiwan mirrors the West in that topics like cancer treatment, its side effects, daily life, and/or future plans are normative discussions amongst family members after the mother's cancer diagnosis. However, this similarity ends when discussion topics include dying and other matters considered in the East as being bad luck or too negative and/or uncomfortable. As mentioned previously, Taiwan, as part of a collectivistic culture, has social norms that limit certain discussions from being openly communicated. On the contrary, in the US, an individualistic culture, it often seems that all topics are open to discussion. Diverging from the Eastern norm, one mother participant with a stage-three recurrence diagnosis, mentioned she discussed death more frequently than any other topics with her daughters. However, when mothers and daughters did have discussions about death, they usually became one-way conversations with little to no participation by the daughters. For example, one mother confronting her death commented:

I am not sure how long I will live-so I told my daughters what I expect them to do and how I envision my funeral, so they will not feel overwhelmed when the time comes. I have to talk about the issue even though this topic makes all of us uncomfortable, but I just want to give all of us enough time to-to prepare.

Another participant with a stage zero diagnosis had a completely different conversational experience with her daughter. After the mother's post-breast cancer surgical recovery, the communication duration, frequency, and depth between her and her daughter were similar to their pre-surgery discussions, but the breadth of the disclosure component expanded. 
Instead of each other's daily lives and thoughts, their focus shifted to more discussion on their future plans, nutrition, and health regimen.

I was really strict and kind of like- "tiger mom" before the diagnosis. The conversation topics between my children and me were always school, school, school. However, maybe because they are getting older and do not live at home...or maybe because my life priority has changed; nowadays, I care about their lives more. Besides topics about their everyday life, I care more about how they live their lives. Do they have a balanced diet? What are their plans after graduation? How are they going to pursue their plans?

Contrary to the typical Eastern reluctance to discuss death, Taiwanese mothers at later cancer stages, do discuss this topic with their family. According to interviewees' responses, one stage-three breast cancer mother attempted to discuss difficult topics such as funeral arrangements and her last words with her children during her mother-daughter communication. However, her efforts at this discussion failed due to non-receptivity of her daughter(s). Another stage-four breast cancer mother had a completely different experience with her daughters. In her case, her children were fully receptive to her disclosure allowing her to share with them her last words and thoughts. It should be noted that the receptivity of the daughters may have been influenced by their ages, with age being an important factor in the mother-daughter breast cancer communication.

\section{Breast Cancer Mothers' Dependency and Their Daughters' Maturity}

The ages of mothers and daughters have far-reaching effects on many aspects of the mother/daughter dynamic. Their ages affect not only both mother's and daughter's ability to face, endure, and cope with breast cancer, they also directly influence the mother's intention of self-disclosure. Further, their ages directly influence mother-daughter breast cancer communication and the types of maternal concerns that accompany a breast cancer diagnosis. Normally in Taiwan, younger breast cancer mothers, those 55 years old or younger, are more independent than older breast cancer mothers. Younger mothers usually just inform their daughters about their cancer progress and treatment information. On the contrary, older mothers are more dependent on their daughters to take care of them, thus their daughters often know more about their mothers' situation than the mothers themselves.

\section{Mothers' Dependency}

Mothers' dependency is influenced by their levels of education and literacy; however, it is their age that ultimately influences these factors. According to Pecchioni et al. (2006), individuals will communicate differently and have different needs across varying ages, but based on this study's interviews, there were certain similar experiences that appeared across all ages of participants. Women in all age groups were open to their daughter(s) about basic diagnosis information, including their breast cancer stage and what treatment(s) they were facing. In fact, many of the older breast cancer patients depended on their family members, especially their daughters, to take them to hospitals. Often daughters knew their mothers' health situation and progress more than their mothers because their daughters had taken charge of communicating with the doctors and all decision making. An 82-year-old breast cancer patient/survivor who was first diagnosed at 77, told the researcher that her daughter told her that there is something bad in her breast and the doctor needs to take it out. The interviewee continued: 
I know the thing in my body probably is not good, but I trust the doctor and my daughter's decision. Staying alive is much more important than loss one side of my breast. Also, I am old enough to not worry my appearance... We went to see doctor together after the surgery, the doctor told us that everything looks ok, and we just need to go back to the hospital to do follow checkups every once in a while... Though the doctor helped me out of the cancer, it was my daughter who provided me support, helped me go through it, and made me believe I will be ok...I cannot imagine what I would be if my daughter was not with me.

The case above represents one segment of aged Taiwanese women who often are financially and physically dependent on their children for support. It is also possible that these women may be illiterate considering the Taiwanese Ministry of the Interior states the illiteracy rate at $17.6 \%$ among women who are 65-years-old and older (Ministry of the Interior, 2015). On the contrary, breast cancer mothers who are younger usually take more control over their healthcare making decisions for themselves because, according to the interviewees, they have a greater ability to access resources and information (e.g., by using the Internet).

Age is an important factor that influences participants' intention to disclose. As one breast cancer survivor recalled, when she first learned her diagnosis at 43 , she felt depressed and overwhelmed. However, she later adjusted and told herself that she was young enough to fight the disease and decided to be a role model for her daughters, showing them the right attitude to face difficulties in life:

\section{Ifeel lucky that I had this disease when I was still young and had energy to fight. At that time, I wanted to show my girls that I am a strong mom and I would be with them when they grew up. I volunteered in the hospital when I felt better. I shared what I saw in the hospital and how I felt and reacted to the situation-I feel through this sharing, my girls became more thoughtful, and as a result, we became closer.}

On the other hand, a 63-years-old breast cancer survivor had totally different motherdaughter communication experiences. When she was first diagnosed with breast cancer at 57, she did not vary her communication with her daughter because they did not live together, and she did not want to worry her daughter. She only told her daughter some general information such as her treatment and medication, but nothing emotional about her concerns and feelings. She told the researcher that, "I can make decisions on my own. There is no need to bother my children and make them worry."

More independent mothers are more likely to take care of themselves and absorb their own negative emotions. This does not mean they do not share or disclose information with their daughters, instead these mothers are selective in the depth of what they choose to share in their mother-daughter communication.

\section{Daughters'Maturity}

The mother-daughter relationship has its impact on breast cancer mothers' disclosure intention. Based on the result of this study's interviews, mothers, regardless of their age or cancer stage, all considered their relationships with daughters either close or very close. However, when facing topics related to cancer diagnosis and treatments, they had different levels of concerns and willingness to disclose. One factor that influenced their willingness to disclose is the age of their daughters. Those with younger daughters may choose to withhold 
negative information because it may worry their daughters and upset the girls' behavior and performance.

Based on the finding from the interviews, unless the daughter(s) were really young, for instance under 10 years old, breast cancer patients/survivors usually told children their basic cancer information, such as the treatment they needed to receive. As to their own emotions, most mothers did not share their emotions with their daughters, especially when daughters were still in primary school. To illustrate a breast cancer mother's concern about causing worry to their daughters, one survivor, with one daughter in middle school and one daughter in high school during the time she was under treatment, said:

During my treatment period, I really hope my children could accompany me, talk to me-but they need to study for school, and they have many exams to prepare for before entering college. Therefore, I always tell myself, "hang in there, do not bother them," even if they are just right next to my room.

Mothers with breast cancer are much more willing to share their treatment, progress, and even diet with their adult daughters. It should be noted that these open lines of communication are not the same for adult sons who are excluded for the most part from the cancer discussions. It is the daughters that received the bulk of information including their mothers' requests that daughters begin to engage in preventative behaviors. One survivor stated that:

\section{I usually share new information I learn from TV or educational lectures with my daughters. Usually, I tell them what to eat and what not to eat...well $\sim$ what not to eat that much, like red meat or deep-fried food. They have a pretty good sense of vigilance already, but I still remind them when I have chance. Vigilance and good habits lower the risk of cancer.}

\section{The Philosophy Of "Face It, Accept It, Deal with It, and Let It Be"}

The phrase of "face it, accept it, deal with it, and let it be" comes from the biography (2009) of Chan Master Sheng-Yen, a Buddhist monk. Though this exact phrase came out recently, this kind of philosophy can be seen in many Chinese classics from more than two thousand years ago, such as Analects (論語), Mencius (孟子), or Daodejing (道德經), using different phrases and descriptions. This philosophy is embedded in Chinese culture and influences the way that people handle difficult situations.

The philosophy of "face it, accept it, deal with it, and let it be" is considered a unique coping strategy in this study. This statement from the Taiwan Breast Cancer Alliance encompasses the first two stages of the philosophy, "most cancer patients usually experience the process of denying, getting angry, negotiating, getting depressed, and finally accepting the situation" (TBCA, 2012). To fully embrace the philosophy, breast cancer patients must first face and accept that they have breast cancer, then deal with the disease, and finally leave their fate to God/ higher power.

In a cancer diagnosis scenario, families are seemingly powerless to control their own outcome, being forced to face the situation involuntarily. However, while the situation is out of their control, breast cancer families can control how they respond to the cancer diagnosis. By practicing this coping strategy philosophy, they can accept their situation faster allowing them to calmly and rationally respond with a willingness to face and deal with the disease. Doctors 
and health prevention professionals generally believe that people who possess this type of attitude are more likely to avoid emotional ruts and to develop the ability to quickly adjust to adverse situations (American Cancer Society, 2014).

The philosophy of "face it, accept it, deal with it, and let it be" is a common theme in the interviews. A breast cancer interviewee noted:

\begin{abstract}
Well...it has already happened. I don't know why I have breast cancer, but... I cannot change anything, right? All I can do now is to face it and deal with it. I have been breast cancer survivor for 14 years, and I am working toward my 15th year of new life. I am fighting for my family. I want to see my daughters to grow up, and I want to see they get married and have their own families.
\end{abstract}

Another breast cancer mother also accepted her illness and tried to look for a positive side in the experience. She mentioned to the researcher how grateful and thankful she was now: "Without experiencing the disease, I probably would not have changed my life values and attitudes. I accept who I am now. I do what I can do to take good care of myself and I follow doctor's instructions. The rest of it, I left to Buddha." Examples like these demonstrate the strength and power of the philosophy of "face it, accept it, deal with it, and let it be." These people reframed their negative opinions about their experiences into a more positive way of thinking. For some people, this kind of attitude may appear passive, however, if thinking this way makes the breast cancer patients/ survivors and their families feel happier and more optimistic in life, it certainly serves a positive function.

The philosophy of "face it, accept it, deal with it, and let it be" has indirect effects on mother-daughter communication among breast cancer families. Breast cancer mothers, who accepted the illness, accepted their fate, and faced the disease in a positive or neutral attitude, were more open to discuss their diseases as well as sharing their emotions with their daughters. Some of these more open, positive breast cancer mothers also went out to educational workshops or seminars to receive the latest information and then share this knowledge with their daughters. Some of them even asked their daughters to go with them. All these interactions had a positive impact on their mother/daughter communication.

\title{
Societal Expectation on Women's Role-The Ideal Image of a Good Mother
}

In Taiwan, as in most societies, there are standards for women in their roles as wives and mothers. Traditionally, the ideal image of a woman is one who assists her husband, raises her children, and takes care of the elderly at home. If the children do not behave or perform well at school, the mother will most likely be considered inadequate in the caring of her children. With these responsibilities and expectations pressuring and constraining women, the added trials of breast cancer may be overwhelming. Patients have to fight against cancer while continuing to perform in their roles of the good wife, mother, and daughter in-law. All participants in this study mentioned that they felt stress from society, their families, and even themselves.

Each participant had her own ideal image of what a good mother looks like, but all participants shared that a good mother is judged by their children's school and work performance as well as children's interpersonal relationship. It is also the expectation of an ideal mother that she worries about her children regardless of how old they are. A breast cancer patient/survivor with two high school daughters described her relationship with her daughters as good. However, when the researcher asked her how frequently and how deeply they communicate with each other, the woman confessed to having a hard time adding substance, such as cancer-related information, and emotion to her communication with her daughter: 
I think my daughters and I have pretty good relationships.... but we barely had any intimate communication recently because they need to prepare for school and exams. I don't want to bother them, and they don't want to bother me either-I know if I want them to come and talk to me, they will, but-I-I just want them to focus on their own work in order to have good grades and to behave well.

A breast cancer mother of an adult daughter also mentioned her communication pattern with her daughter:

My daughter is very busy. She owns three clothing stores and she lives by herself. We barely see each other because of her busy schedule, but we talk on the phone sometimes. Hmm...probably once every two weeks. I would say-besides general greetings or catch up for each other's news, we don't go anything further. Don't get me wrong. We are close. I just don't want to bother her... She is busy.

\section{Religion}

Confucianism, Buddhism, Taoism, and other folk religions heavily impact the Taiwanese culture. The Confucian thoughts, the values of various religions, and many other Chinese traditions provide guiding principles for people to follow, learn, and socialize. Perhaps most importantly in informing this study, religion assisted people in finding their inner peace.

Among the fifteen mother participants, most of them were already religious believers before they were diagnosed with breast cancer, but they were lax in practicing their beliefs. Interestingly, they became active believers after their diagnosis and described many shared experiences with other mother participants. They all felt peaceful and brave when they sought support from religion. A breast cancer mother who had recently experienced a recurrence shared her religious experiences with the researcher:

I transcribed Buddhism and Confucian classics during the treatment and even now-I feel much more peaceful and stable through doing this. In my opinion - I become more optimistic and stronger because of my religion - when I talk to my daughter, I was not as pessimistic as before and sometimes I can even calm my daughter down.

Religious beliefs bring a positive impact on mother-daughter communication among these breast cancer families. Since the breast cancer mothers had faith, they were not afraid to face the possibility of death and this gave them encouragement to talk about death with family members. A stage III recurrence breast cancer mother noted:

I have planned everything already, from current lifestyle and activities participation to my plan for the funeral. I am pretty calm now. I don't want to do any treatments anymore. I tried once-a very painful and struggled one, but it failed. I don't want to experience same process again. I have a strong faith and I believe Jesus will guide me. I told my family take it easy and pray for me. We are all Christians. They will understand me and support me. 


\section{Support Group Engagement}

Getting involved in community services and having increased communication with a support group helped breast cancer patients/survivors know that they were still a valued part of their family and the society. In the group, they not only received support from others, but also offered their support to others. Through interacting and mutually supporting each other, breast cancer mothers escaped feelings of being trapped in their own world and feeling miserable all the time. In contrast, contact with support groups gave breast cancer mothers opportunities to open their eyes to experiencing the true meaning of life. But perhaps most importantly, support groups provided participants with a sense of belonging and identity-reinforcement that had been missing since receiving their life-altering cancer diagnosis.

Among these participants, nine of them joined support groups. These participants were the main caregivers of the family; however, after being diagnosed with breast cancer, they became the ones who needed care from others. This kind of change affected their communication with their daughters as most mothers struggled to redefine their values and their role in the family; hence, they looked for outside resources to reconstruct their values. Support groups gave breast cancer mothers the tools to rebuild their values and confidence. The patients/survivors were not only the beneficiaries of support; they also benefited from being able to provide support to others. The benefits resulted in mothers being happier, more productive, and better adjusted, which, in turn, brought about attitudinal changes that positively influenced the ways they communicated with their daughters.

\section{Breast Cancer Support Group Participation}

Breast cancer support groups provided different kinds of support to breast cancer patients/ survivors. In addition to working with the hospitals and healthcare providers to hold various educational workshops, support groups also visited new patients and organized events to create bonds and encourage group members' support of each other. These activities helped breast cancer mothers feel useful and needed gaining extra confidence by supporting others. Additionally, mothers benefitted from the camaraderie and shared cancer experience of others within the group. A survivor who participated in support group for eight years mentioned that:

I feel I am useful and valuable again-I help and give advice to new patients. I cooperate with doctors, nurses, and hospitals to hold educational lectures and workshops. All these activities make me feel I am not useless, which make me to love myself more, and the most important thing is, I share what I learn and what I see in the support group with my daughters-I don't know, I feel like I am not as weak as before-I can provide new information to my family. I can educate them-I am a mom again.

\section{Hospital and Community Volunteer Group Participation}

Besides joining breast cancer support groups, volunteering in hospitals or in the community also provided another opportunity to broaden breast cancer patients/ survivors' horizons. Similar to participants in breast cancer support groups, breast cancer mothers found their values and sense of self through helping others. A survivor who volunteers in the hospital for several years said:

I learned a lot from other patients. I saw similar emotions such as depression, anger, and helplessness across all types of cancer patients. 
Doing volunteer work makes me realize that I am not in the worst situation-so many people are suffering now. I can still go out and help, but they can only lie on the beds and wait-wait for the day to come. I-I appreciate what I have now. Hmm...I told my children what I saw when doing volunteer work. I expressed my appreciation. I am not sure if this kind of conversation would influence their opinions or behaviors, but I hope they can be more content and grateful.

\section{Discussion}

This study was designed to explore factors that influence mother-daughter communication about breast cancer in Taiwan. Though several previous studies have addressed parent-child communication in Taiwan, most of them are about sexuality (Kang, 2010; Lai, 2008), education (Huang, 2014; Hsu, 2005) and personality development (Wu, 2011). There is still a dearth of information regarding health-related issues, including mother-daughter cancer communication.

The research question focused on the role of individual, relational, and cultural factors in breast cancer mothers' intention of self-disclosure. Various factors had an impact on individuals' intention to self-disclose. In this research, six themes emerged from the interview data. (1) the cancer stage when the mother was first diagnosed with breast cancer, (2) breast cancer mothers' age and their daughter's maturity when breast cancer was diagnosed, (3) the philosophy of "face it, accept it, deal with it, and let it be," (4) societal expectations on women's roles, (5) religion, and (6) support groups. Some themes can only be placed into one category as illustrated by the mother-daughter relationship that can only be categorized as a relational factor. Other themes are difficult to classify into only one single category, as they exert influence on multiple levels. Age can be utilized as an example to demonstrate this point; "aged identity" as defined by Hockey and James (2003) is a self-identity that is shared and shaped by "culturally specific social roles and experiences" (p.82). An individual's "aged identity," therefore, is influenced by society's expectations, which makes it both an individual factor and a cultural factor.

There were a few notable findings from the interview data. First, a mother's age and her daughter's age at diagnosis along with the mother's cancer stage all impact the mother's disclosure intention. These findings are consistent with previous studies (Spira \& Kenemore, 2000; Raveis \& Pretter, 2005), which demonstrated that the mothers' illness can have profound and multifaceted impact on their children, whether their children are school-aged or adults. These data highlighted the influence of mothers' cancer stage and their children's maturity on their communication, particularly communication about cancer. In general, mothers in advanced cancer stages grasped and cherished every opportunity for mother-daughter conversation. When such conversations did happen, they also tended to be deep and meaningful.

Second, socioeconomic status also played an important role in mother-daughter breast cancer communication. Previous research has demonstrated similar results where socioeconomic status significantly affects survival rates, quality of life, prevention behaviors, and family communication (Von Wagner et al., 2011; Fagundes et al., 2012). Den Heijer et al., (2011) found that open family communication about hereditary cancer resulted in "less general and breast cancer specific distress" (p.1317). Den Heijer and colleagues (2012) also pointed out that the more plentiful one's personal resources (wealth), the more positive the impact of one's social resources on psychological distress. This study demonstrated that, without financial pressure, breast cancer mothers can concentrate more on their own health, and consequently, have more energy and better communication with their children.

Third, society's expectations on women's roles influenced breast cancer mothers' willingness to disclose themselves in different ways. Mothers usually want to provide the best 
and the most abundant resources to their children. Whether their children are young or adults, in school or at work, the mothers usually try their best to support their children even when it means sacrificing their own needs. Breast cancer mothers chose to bear the burden of stress and discomfort by themselves, withholding their emotions from their families because they do not want to bother and worry their children. The depth, breadth, frequency, duration, valence, and veracity of the breast cancer patients/survivors' self-disclosure are all greatly influenced by these concerns.

\section{Limitation}

This study fills a need in mother-daughter breast cancer communication research by examining different levels of factors that may influence breast cancer mothers' self-disclosure intentions. While this research offers a new look into this particular relationship from a unique perspective, it does have some limitations.

First, there are limitations attached to snowball sampling as a recruitment tool in that this method often results in participants who share backgrounds, socioeconomic status, education etc. Depending on the participant pool, they might also share like-minded traits such as political affiliation or religious beliefs. The pool of this study was drawn from personal contacts and participant referrals from religious organizations and support groups in hospitals. Therefore, it should come as no surprise that the participants shared a strong religious faith or had found the value in participating in cancer support groups, and in some cases both. Thus, breast cancer mothers without a religion or who do not participate in any support groups were, through no intention of the researcher, excluded. This could be considered problematic in presenting a bias. Although the results did show that religion and support group engagement have significant meaning on the breast cancer patients'/survivors' coping strategies, those who do not participate also need to be considered.

Second, the interviewees in this study all self-reported to have fairly high socioeconomic status. Those who suffered severe financial pressures were most likely to be unintentionally excluded from this study. This becomes problematic in that this sample of women from a higher socioeconomic class are privileged with more access to resources and the luxury of having the time to join support groups. This group does not fairly represent the many breast cancer patients/survivors who experience financial constraints that drastically limit their choices. Future studies need to include a better range of socioeconomic groups, from the privileged to underprivileged, to better capture the experiences, communication, and limitations of breast cancer patients/survivors.

\section{Implications}

\section{The Role of Hospitals and Physicians}

Physicians project the image of intelligence and authority, and often their influence on their patients and the public was not fully grasped (Chen \& Chong, 2002). Though this study investigates the factors that impact breast cancer mothers' cancer communication intentions, it does provide insight into the importance of physicians in the mother/daughter discussion dynamic. For example, by spending just a couple of extra minutes in conversation with breast cancer patients and their family members, physicians can remind those present of the importance of having open and informative mother-daughter breast cancer communication strongly emphasizing the daughters' genetic predisposition to contracting the same disease. Physicians can also instruct family members on the importance of cancer prevention behaviors and, as highly respected members of society, have their advice embraced and adopted. 
Additionally, this study demonstrates the positive outcomes for breast cancer patients/survivors who are involved in support groups. The multitude of benefits features not only an avenue to gaining new information on healthcare and prevention behaviors, but also provides vital mental health benefits such as increased self-esteem and sense of purpose. It should be noted that support groups are widely available in Taiwan, being required at almost all medium-sized or comprehensive general hospitals as a component for the hospital's accreditation (Health Promotion Administration, 2014). Moreover, this study offers valuable justification for hospitals and healthcare providers to remain steadfast in maintaining support group services. Once again, the influence of physicians can be utilized in encouraging new breast cancer patients to participate in support groups by explaining the positive outcomes that result from this activity, and how these positive outcomes tie directly to patients' quality of life.

\section{The Role of Support Groups}

A support group usually consists of patients/survivors, healthcare professionals, and social workers. One of the fundamental activities of the group is to hold educational workshops, which often focus on new treatments and medicine. However, workshops and/or discussions on patients' mental health and family communication are rarely introduced. Identity selfadjustments, such as the process of patients/survivors' progression from diagnosis through acceptance, and cancer communication are integral components that require attention. Support groups are the ideal vehicle to introduce these sensitive topics because breast cancer patients/survivors may be more willing to share their situations and concerns with others who have gone and are going through similar emotional challenges. If efforts, including support groups, were made to improve breast cancers mothers' level of information, strategies for family cancer communication, family bonding activities, and mental health outlooks, this could in turn positively impact the mother-daughter cancer communication. It has the potential to pave the way for an even closer mother-daughter relationship with more frequent and deeper cancer discussions.

\section{The Role of Government}

Taiwanese government has shown a commitment to breast cancer prevention by offering free mammograms for all women over 45 and those 40-44 with a family history of breast cancer. Local health bureaus, which operate under the direction of the Taiwanese government, perform extensive outreach by going into communities, especially remote location, in an effort to recruit women to take mammograms. This outreach would provide an excellent opportunity for local health bureaus to promote the effectiveness of mother-daughter cancer communication and its influence on their daughters' prevention behaviors. By planting this into the communities, the government can raise awareness of not just breast cancer patient/survivor mother-daughter cancer discussion, but of the benefits of all cancer and general open family communication. Additionally, as awareness of breast cancer becomes more commonplace in Taiwanese society, it may also have a transformative effect on the stigma attached to the disease and the negative stereotype attached to being "less than" society's ideal female image.

The government could develop better programming, publicity, and outreach communicating the importance of mother-daughter communication. This would be a more effective technique than using fear to package general information on how important diligent breast care is to women's health. The Taiwanese government should also commit more funding for research on the outcomes of family and health communication. This study should serve as evidence of the importance and influence of family communication and provide justification that these areas of research deserve more attention, resources, and funding. 


\section{References}

American Cancer Society. (2014). Attitudes and Cancer. Retrieved from http://www.cancer.org/treatment/treatmentsandsideeffects/emotionalsideeffects/attitud es-and-cancer

Badr, H., \& Taylor, C. L. C. (2006). Social constraints and spousal communication in lung cancer. Psycho-Oncology, 15, 673-683. DOI: 10.1002/pon.996

Bigatti, S. M., Wagner, C.D., Lydon-Lam, J.R., Steiner, J. L., \& Miller, K. D. (2011). Depression in husbands of breast patients: relationships to coping and social support. Supportive Care in Cancer, 19 (4), 455-466.

Cahn, D. D. (1984). Communication in interpersonal relationships in two cultures: Friendship formation and mate selection in the U.S. and Japan. Communication, 13, 31-37.

Chan. (2009). Footprints in the Snow: The Autobiography of a Chinese Buddhist Monk. Punsuculture.

Chen, G. M. (1995). Differences in self-disclosure patterns among Americans versus

Chen, P. H., \& Yo, S. Y. (2001). Cultural and family therapy in Taiwan. Asian Journal of Counseling, 8 (2), 153-174.

Chen, Y., \& Chong, D. (2002). Our perspective on physicians' ethical development. Retrieved from http://www.ncu.edu.tw/ phi/NRAE/newsletter/no21/05.pdf

Chinese: A comparative study. Journal of Cross-Cultural Psychology, 26(1), 84-91.

Collins, N. L., \& Miller, L. C. (1994). Self-disclosure and liking: A meta-analytic review. Psychological Bulletin, 116 (3), 457-474

Den Heijer, M., Seynaeve, C., Vanheusden, K., Duivenvoorden, H. J., Bartels, C. C. M., MenkePluymers, M. B. E., \& Tibben, A. (2011). Psychological distress in women at risk for hereditary breast cancer: the role of family communication and perceived social support. Psycho-Oncology, 20,1317-1323. DOI: 10.1002/pon.1850

Den Heijer, M., Vos, J., Seynaeve, C., Vanheusden, K., Duivenvoorden, H. J., Tilanus-Linthorst M., Tibben, A. (2012). The impact of social and personal resources on psychological distress in women at risk for hereditary breast cancer. Psycho-Oncology, 21,153-160. doi: $10.1002 /$ pon. 1879 .

Fagundes, C. P., Lindgren, M. E., Shapiro, C. L., \& Kiecolt-Glaser, J. K. (2012). Child maltreatment and breast cancer survivors: Social support makes a difference for quality of life, fatigue and cancer stress. European Journal of Cancer, 48, 728-736.

Fisher, L. R. (1991). Between mothers and daughters. Marriage and Family Review, 176 237248.

Frank, G., Bertos, N., Pepin, F., Sadekova, S., Souleimanova, M., Zhao, H., Chen, H., Omeroglu, G., Meterissian, S., Omeroglu, A., Hallett, M., \& Park, M. (2008). Stromal gene expression predicts clinical outcome in breast cancer. Nature Medicine, 14, 518-527. doi:10.1038/nm1764

Gaber, R., Desai, S., Smith, M., Eliers, S., Blatt, H., Guevara, Y., \& Robinson, J. K. (2013). Communication by mothers with breast cancer or melanoma with their children. International Journal of Environmental Research and Public Health, 10 (8), 3483-3501. http://dx.doi.org/10.3390/ijerph10083483

Gao, G. (1996). Self and other: A Chinese perspective on interpersonal relationships. (W. B. Gudykunst, S. Ting-Toomey, \& T. Nishida, Ed). Sage.

Goodwin, P. J., Leszcz, M., Ennis, M., Koopmans, J., Vincent, L., Guther, H., Drysdale, E., Hundleby, M., Chochinov, H. M., Navarro, M., Speca, M., \& Hunter, J. (2001). The effect of group psychosocial support on survival in metastatic breast cancer. New England Journal of Medicine, 345(24), 1719-1726.

Gudykunst, W. B., \& Shapiro, R. (1996). Communication in everyday interpersonal and 
Guerrero, L. K., Andersen, P. A., \& Afifi, W. A. (2014). Revealing and hiding ourselves: Selfdisclosure and privacy. (L. K. Guerrero, P.A. Andersen, \& W. A. Afifi, $4^{\text {th }}$ Eds.). Sage.

Hockey, J. \& James, A. (2003). Social identities across the life course. Palgrave Macmillan.

Hofstede, G. (1980). Culture's consequences: International differences in work-related values. Sage.

Hsu, S. (2005). Research on the relationship between parent-child co-learning and parentchild communication [Unpublished master's thesis]. National Kaohsiung Normal University.

Huang, J. (2014). A Study on the Relationship between the Participation of Family Leisure Activity and Parent-children communication of Fifth and Sixth Grade Elementary School Students in Yunlin County [Unpublished master's thesis]. National Kaohsiung Normal University. intergroup encounters. International Journal of Intercultural Relations, 20, 19-45.

Jourard, S. M. (1971). Self-disclosure: An experimental analysis of the transparent self. Wiley. Kang, Y. (2010). Relationships between Gender Attitude and Sex Role in Elementary School Students in Kaohsiung [Unpublished master's thesis]. National Pingtung University.

Kroenke, C. H., Rosner, B., Chen, W. Y., Kawachi, I., Colditz, G. A., Holmes, M. D. (2004). Functional impact of breast cancer by age at diagnosis. Journal of Clinical Oncology, 22 (10), 1849-1856. DOI: 10.1200/JCO.2004.04.173

Lai, Y. (2008). Parent-child Communication about Sex-related Topics [Unpublished master's

Lichtman, R. R., Taylor, S. E., \& Wood, J. V. (1998). Social support and marital adjustment after breast cancer. Journal of Psychosocial Oncology, 5 (3), 47-74. DOI:10.1300/J077v05n03_03

Mallinger, J. B., Griggs, J. J., \& Shields, C. G. (2006). Family communication and mental health after breast cancer. European Journal of Cancer Care, 15, 355-361.

Manne, S., Badr, H., Zaider, T., Nelson, C., \& Kissane, D. (2010). Cancer-related communication, relationship intimacy, and psychological distress among couples coping with localized prostate cancer. Journal of Cancer Survivorship, 4 (1), 74-85.

Marshall, C., \& Rossman, G. (1995). Designing qualitative research (2nd ed.). Sage.

Meleshko, K. G., \& Alden, L. E. (1993). Anxiety and self-disclosure: Toward a motivational model. Journal of Personality and Social Psychology, 64, 1000-1009. doi: 10.1037/0022-3514.64.6.1000

Milbury, K., \& Badr, H. (2013). Sexual problems, communication patterns, and depressive symptoms in couples coping with metastatic breast cancer. Psycho-Oncology, 22 (4), 814-822. DOI: $10.1002 /$ pon.3079.

Ministry of Health and Welfare. (2014). 2013 statistics of causes of death. Retrieved from https://dep.mohw.gov.tw/DOS/np-1784-113.html

Ministry of the Interior. (2015). 2014 statistics of education among people who are 15 years old. Retrieved from http://www.moi.gov.tw/stat/week.aspx

Montazeri, A., Jarvandi, S., Haghighat, S., Vahdani, M., Sajadian, A., Ebrahimi, M., \& HakoMahmoodi, M. (2001). Anxiety and depression in breast cancer patients before and after participation in a cancer support group. Patient Education and Counseling, 45 (3), $195-$ 198.

Pecchioni, L. L., Thonpson, T. L., \& Anderson, D. J. (2006). Interrelations between family communication and health communication. (L.H. Turner \& R. West, Eds.). Sage Publications.

Peng, Y. (2008). Marital immigration, cultural disadvantaged, and the performance of motherhood: The debate of domination and resistance [Unpublished master's thesis]. National Pingtung University.

Petronio, S. (2002). Boundaries of privacy: Dialectics of disclosure. SUNY Press. 
Raveis, V. H., \& Pretter, S. (2005). Existential plight of adult daughters following their mother's breast cancer diagnosis. Psycho-Oncology, 14, 49-60.

Roberts, M. E., Gerrard, M., Reimer, R., \& Gibbons, F. X. (2010). Mother-daughter communication and Hunan Papillomavirus Vaccine uptake by college students. Pediatrics, 125 (5), 982-989. DOI: 10.1542/peds.2009-2888.

Rodriguez, E. M., Dunn, M. J., Zuckerman, T., Vannatta, K., Gerhardt, C. A., \& Compas, B. E. (2012). Cancer-related sources of stress for children with cancer and their parents. Journal of Pediatric Psychology, 37 (2), 185-197. DOI: 10.1093/jpepsy/jsr054

Shenkar, O., \& Ronen, S. (1987). Structure and importance of work goals among managers in

Sinicrope, P. S., Patten, C. A., Clark, L. P., Brockman, T. A., Frost, M. H., Petersen, L. R., Vierkant, R. A., Vachon, C. M., Fredericksen, Z. S., Janney, C. A., Sellers, T. A., \& Cerhan, J. R. (2009). Adult daughter's report of breast cancer risk reduction and early detection advice received from their mothers: an exploratory study. Psycho-Oncology, 18, 169-178. DOI: 10.1002/pon.1393

Spira, M., \& Kenemore, E. (2000). Adolescent daughters of mothers with breast cancer: Impact and implications. Clinical Social Work Journal, 28, 183-195.

Strauss, A., \& Corbin, J. (1990). Basic of qualitative research: Grounded theory and techniques. Sage.

Strauss, A., \& Corbin, J. (1998). Basics of qualitative research ( $2^{\text {nd }}$ ed.). Sage.

Taiwan Breast Cancer Alliance (TBCA). (2012). About TBCA. Retrieved from http://www.tbca-npo.org.tw/about.asp

Tercyak, K. P., Mays, D., DeMarco, T. A., Peshkin, B. N., Valdimarsdottir, H. B., Schneider, K. A., \& Patenaude, A. F. (2013). Decisional outcomes of maternal disclosure of BRCA1/2 genetic test results to children. Cancer Epidemiology Biomarkers Prevention, 22. DOI: 10.1158/1055-9965.EPI-13-0198

the People's Republic of China. The Academy of Management Journal, 30, 564-576. thesis]. National Taipei University of Education

Till, J.E. (2003). Evaluation of support groups for women with breast cancer: Importance of the navigator role. Health and Quality of Life Outcomes, 1, 1-16. https://doi.org/10.1186/1477-7525-1-16

Vangelisti, A. L. (2004). Preface. (A. L. Vangelisti, Eds.). Lawrence Erlbaum Associates, Inc.

Von Wagner, C., Baio, G., Raine, R., Snowball, J., Morris, S., Atkin, W.,...Wardle, J. (2011). Inequalities in participation in an organized national colorectal cancer screening programme: Results from the first 2.6 million invitations in England. International Journal of Epidemiology, 40, 712-718. doi: 10.1093/ije/dyr008

West, M., Blanchette, C., Dressman, H., Huang, E., Ishida, S., Spang, R., Zuzan, H., Olson Jr., J. A., Marks, J. R., \& Nevins, J. R. (2001). Predicting the clinical status of human breast cancer by using gene expression profiles. Proceedings of the National Academy of Sciences, 98, 11462-11467.

Wu, R. (2011). A Study on the Relationships Between Parent-children Communication and Frustration Tolerance of Elementary School Students [Unpublished master's thesis]. National Kaohsiung Normal University. 


\section{Notes on Contributor}

Wan-Lin Chang, Ph.D. is an assistant professor at the Department of Communication at the University of Texas Rio Grande Valley. Dr. Chang graduated with her master's degree in International Health Policy and Management from Brandeis University in 2018 and with her Doctorate in Communication in 2015 from George Mason University. Dr. Chang has publications in peer-reviewed journals and has provided more than 40 presentations at the local, state, national, and international levels. Dr. Chang's research interests include health promotion, health communication, family communication, and instructional communication.

Manuscript received June 11, 2021 Final revision received September 25, 2021 Accepted September 26, 2021 